\title{
Analytical Review of Application of Problem Tree Analysis As a Project Design Tool For Enhancing Performance of Community Based in Kenya
}

\author{
Wasike Wilberforce Walubengo, Dorothy Ndunge Kyalo, and Angeline Sabina Mulwa
}

\begin{abstract}
The purpose of this study was to establish how application of problem tree analysis influences performance of community based projects in Kenya. The study was employed descriptive research design. A sample of 128 was obtained from a target population of 192 respondents through stratified random sampling procedure from different community based organizations. Data were collected by a questionnaire and an interview guide. Qualitative data was analyzed through checking data, developing codes, identifying themes and patterns. Data was summarized then linked to the objectives and hypotheses. Quantitative data was analyzed where both descriptive and inferential statistics was generated. Descriptive results were presented as frequency tables, percentages, arithmetic means and standard deviation. Inferential statistics were analyzed using Pearson's Product Moment correlation ( $r$ ) from simple regression and multiple regression analysis. F-test was used to test the hypotheses. Tests of statistical assumptions were carried out before analysis. In this study; $R^{2}=0.214 ; F$ (8.971) at $p=0.000<0.05$; therefore, $H_{0}$ was rejected and it was concluded that the application of project tree analysis has statistically significant influence on the performance of community based projects. In conclusion, the most dominant indicator was project problem identified, followed by project root causes and project effects. The application of project tree analysis had a statistically significant influence on the performance of community based projects. The findings add to Project Management Body of Knowledge by empirically proving that the application of project tree analysis had statistically significant influence on the performance of community based projects.
\end{abstract}

Index Terms-Problem Tree Analysis, Project Design Tools, Performance of Community Based Projects

\section{INTRODUCTION}

Globally, development of overall performance has emerged as ever more essential to the success of projects and has been the concern of a considerable amount of studies and interest during the last decades. Smyth (2010) mentioned that there has been several projects throughout many nations over the past 10 to fifteen years to introduce reform to the project process and more particularly, on the tools used at project design phase with a purpose to enhance overall performance. Regardless of the reality that globally there are a number of projects that have been carried out properly, there is but an issue related to the common and prolonged delays which have triggered under-fulfillment in project overall performance which relate to project layout (Al- Kharashi \& Skitmore, 2009). In a big and complex project, design frequently entails more than one individual or groups participating in a design process, sharing design data, negotiating and making decisions, coordinating and handling design obligations and activities (SAD, 2008). Consequently, the effectiveness of collaborative design procedure will become vital for design project management. At the same time, the way to enhance the effectiveness of a collaborative project design is a tough issue within the discipline of collaborative design with the intention to enhance performance (Kalsaas, 2012).

Governments, Non-Governmental organizations (NGOs) and personal businesses within the developing world particularly, are more and more engaged in donor-funded projects. They are frequently requested to formulate project proposals which can be economically, socially, politically and environmentally feasible. To address those regularly complicated and stressful processes, project managers need to own the present day understanding on diverse project design tools. Project design tools have advanced lately (Burke, 2013). The inconsistencies among design and project specifics that have a substantial effect on project performance in Saudi Arabi, have been identified by (Abegunde, 2014). The European commission (2004) as an instance added a new method to the log frame matrix and the World Bank is promoting a brand new method for the financing of development interventions.

In Kenya, and more particularly Bungoma County, community primarily based projects are set up with the aid of collective efforts of indigenous people of homogenous or heterogeneous attributes however residing or working in the same environment. Their coming together creates situations which expand the base of self-governance and diffusion of power thru a much broader circle of the populace (Adeyemo, 2012). It is seen as voluntary, non-profit, non-governmental and exceptionally localized or neighborhood establishments whose membership is positioned on equal level and whose predominant purpose is the development of the social and financial wellness of each member (Abegunde, 2014). These are processes wherein efforts of the people are united with those of government authorities and development aid organizations. They accomplish that to enhance the financial, social and cultural situations of communities. They combine them into the lifestyles of the nations and to allow their 
members to make contributions absolutely to countrywide development (United Nations, 2008). The Oxford university Press (2000) argues that community improvement affords avenue for people to prepare themselves for planning action; outline their common and character needs and problems; make group and individual plans to fulfill their desires and remedy their issues; execute these plans with a maximum reliance upon community assets; and, complement these resources whilst necessary with services and materials from authorities and non-governmental corporations outside their communities. This study focused on how the application of problem tree analysis influences performance of community based projects in Bungoma County.

Problem tree analysis identifies the negative aspects of an existing situation and establishes the cause and effect' relationships between the identified problems (Pinto, 2018). It involves three main steps: definition of the framework and subject analysis; identification of the major problems faced by target groups and beneficiaries; and visualization of the problems in form of a diagram, called a problem tree or hierarchy of problems to help analyze and clarify cause-effect relationships (Burke, 2013). Long (2004) stated that a clear problem analysis thus provides a sound foundation on which to develop a set of relevant and focused project objectives. Once complete, the problem tree represents a summary picture of the existing negative situation. In many respects the problem analysis is the most critical stage of project planning; it guides all subsequent analysis and decisionmaking on priorities (Magano, 2008).

Like any other tree, the problem tree has three parts: a trunk, roots; and branches. The trunk is the core problem. The roots represent the causes of the core problem and the branches represent its effects. Like the roots of a tree, the causes of the core problem are not always immediately apparent, but if one does not understand the causes, there is little one can do to address the problem (McConville, 2007). Mwaura (2014) argues that understanding the core problem and its causes is important if the project is to effectively address the effects of that problem on the community. The problem tree is one method of mapping out core problems, along with their causes and effects, helping project planners to identify clear and manageable objectives (Nyonganyi, 2013).

\section{Statement of the Problem}

Effective use of project design tools is considered one of the key aspects of project performance. Project management is a challenging task with many complex responsibilities and the relevant project design tools and techniques. Even though there are many tools available to assist with accomplishing the tasks and executing the responsibilities, project managers face a problem of choosing the best project design tool that suits their management style and addresses all project management needs (Silverman, 2008). In third world countries in Africa like Kenya, national and regional governments, local and international NGOs and other concerned organizations invest large sums of money every year on various projects. Even with the continuous efforts to ensure community based projects guarantee performance and success, failure to have in place effective project designs and other avoidable factors from initial stages to performance completion is still too low. The improvement of performance of community based projects has become ever more critical to the success of projects and has been the subject of a considerable amount of research and attention over the past two decades.

Research has shown that CBPs full potential has yet to be tapped due to the existence of several constraints such as lack of planning, improper financing and poor management (Mkutu, 2011). Poor or a lack of project design has also been identified as one of the most serious constraints facing CBP and hindering their profitability (Odindo, 2009). According to Bungoma County Integrated Development Plan (2016), there are about 96 registered CBPs in the region being carried out in different areas. The Bungoma County plan indicates that they expect the CBPs to contribute more than $3 \%$ to the development of the county by providing the services in various interest areas. Despite this, their contribution is still below the expected rates which, therefore, led to the current study on the influence of application of project design tools on performance of community based projects in Bungoma County. Additionally, it is not an easy task to sustain radical improvement in a diverse environment such as in the project industry. This requires the identification and implementation of suitable improvement programmes subjected to the project business cycle. This is important since the integration of improvement framework design in community based projects may incur high cost and yet the benefit can only be realized in the long term (Chikati, 2009). However, there is a need for new improvement framework design and initiatives at various stages of a project life-cycle in order to enhance project performance and target changing trends of private and public sector project organizations (Smyth, 2010).

Stare (2012) on the other hand carried out a study to establish the impact of the organizational structure and project organizational culture on project performance in Ugandan enterprises, the study only dealt with establishing the impact of the organizational structure and project organizational culture on project performance. It did not address the interaction of project design tools, project manager's competencies and performance of community based projects. The current study sought to establish the influence of application of problem tree analysis on performance of community based projects in Bungoma County, since these studies did not give any conclusive evidence to show the link between application of problem tree analysis and performance of community based projects. The study was guided by the following objective: To examine how application of problem tree analysis influences performance of community based projects in Bungoma County.

\section{LITERATURE REVIEW}

On why a problem tree should be created, Campbell et al. (2006) in their study established that creating a problem tree should ideally be undertaken as a participatory group event using visual techniques, such as flipcharts in which identified stakeholders can write their individual problem statements. $\mathrm{He}$ further argues that a properly planned project is 
addressing the real needs of the beneficiaries and is therefore based upon a correct and complete analysis of the existing situation. The existing situation should be interpreted according to the views, needs, interests and activities of parties concerned. It is essential that all those involved participants accept the plans and are committed to implementing them. The importance of problem tree analysis according to Paul (2005), is that it helps the planning of a project, provides a guide as to the complexity of a problem by identifying the multiple causes; identifies particular lines of intervention and other factors that may need to be tackled with complementary projects and provides an outline of the project plan, including the activities that need to be undertaken, the goal and the outcomes of the project.

Problem identification is important in developing the capacity of grassroots communities, argues Mulwa (2008). Community development as a process begins with needs problem identification. When they do this together the community members can share the vision and commit to seeing it become a reality. What follows are sessions where the problems identified are discussed critically and analyzed objectively. This is aimed at understanding the problem clearly and appreciating their magnitude. The scope and clarity of the problem and cause effect relationships are identified during this stage. Resources available to address the problems are also identified. During this stage the community will identify several problems but should be able to prioritize and order them from the most pressing to the least pressing needs. Similarly, the beneficiaries should assess the needs by identifying the cause-effects relationships and considering their resource endowment.

During initiation, a needs analysis by stakeholders can serve as a guide to ensure that the project design is in line with the root causes of the problems identified of the said community according to Chikita (2009) in his study on participatory project identification and planning, a regional partnership for resource development publication. The study was undertaken to demonstrate how stakeholder participation in identification of root causes influence the performance of donor funded projects. A total sample size of 70 was used in the study. Descriptive design was used to analyze data; specifically, the researcher used SPSS and mainly measures of central tendency were used to describe data. He concluded that the guiding principle in deciding whether community participation is possible and practical during project execution is the identification of root causes. The facts of root causes found in the preliminary stage are valuable in reaching a successful conclusion. This study was carried out in Nairobi and could not be generalized on projects operating in the local setup. This led to the current study which sought to establish how root causes in problem tree analysis influence community based projects in Bungoma County.

Conducting a problem tree is an important aspect for project managers. According to McCawley (2014), conducting a problem tree or a solution tree analysis provides a means of reviewing the existing understanding of the effects and causes to a specific problem and how it can be overcome. A problem tree will likely reveal multiple branches of cause and effect relationships leading to the core problem. This is very valuable as it identifies factors that may not be addressed by the planned intervention. He further argues that existing regulations may be a factor in the problem, but this may not be impacted upon by the planned intervention. This may result in the failure to achieve project objectives. It could be that impacting upon regulation is not achievable and thus out of scope for the project. This study sought to establish the influence of problem tree analysis cause-effect relationship, while the current study sought to establish the independent relationship among variables such as identified problems, root causes and the effects against community based performance.

Using the problem tree analysis, a problem can be broken down into manageable and definable chunks as argued by White and Walker (2012). Since this enables clearer prioritization of effects and causes and helps focus objective; there is better understanding of the problem and its often interconnected and even contradictory effects. This is often the first step in finding win-win solutions. They further found out that it identifies the constituent issues and arguments, and can help establish who and what the political actors and processes are at each stage; it can help establish whether further information, evidence or resources are required to make a strong case, or build a convincing solution; presents issues rather than apparent, future or past issues are dealt with and identified; and, the process of analysis often helps build a shared sense of understanding, purpose and action. The primary data collection was questionnaire and data were analysed through regression analysis. The study tested for direct linear relationship between the independent and dependent variables. The current study tested for the moderating effect of managers' competencies between the variables.

This study is grounded on the resource-based view (RBV) of the firm first proposed by Wernerfelt. He postulated that with effective planning of strategic resources and core competencies by the firm, sustained competitive advantage are achieved leading to superior firm performance. Collis and Montgomery (2014) supported the RBV proposition when they analysed competitive advantage from the resource-based view perspective, concluding that resources and capabilities are valuable source of sustained competitive advantage if well managed and planned for. However, Tarboda (2010) suggested that these characteristics of firm resources and capabilities cannot sustain competitive advantage since competitors will soon begin to acquire the same resources through imitation or substitution. From a corporate strategy point of view, Pearce and Robinson (2007); and Peteraf and Bergen (2003) argued that the firm's resources and core competencies fundamentally determine firm strategies and the plans that an organization has in place. Hoffmann (2010) contends that for a firm to arrive at a better determined corporate strategy, it is important to conceive its resources as capacities towards superior performance. On his part, Leiblein (2003) argued that the RBV contemplates how firm resources are allocated and deployed in corporate strategy plans. Therefore, firm corporate strategy can be established by focusing on integration of firm resources (Furrer, Thomas and Goussevskaia, 2009).

According to Peteraf and Bergen (2003) the purpose of corporate strategy is to manipulate strategic resources and core competencies into new configurations to acquire and sustain competitive advantage. Therefore, firms must determine the correct corporate strategies based on strategic resources and core competencies (Tarboda, 2010). However, 
some scholars have criticized the theory. For instance, Lockett, Thompson and Morgenstern (2009) argued that the RBV assumes that firms are profit maximizing entities operating in distinctive markets with the assumption that the future value of firm resource is asymmetrically distributed through planning. Other critiques include that RBV has no competitive implications in unpredictable and unstable environments (Hoffmann, 2010). Further, Miller (2003) suggested that only firms that already possess valuable, rare, inimitable and non-substitutable (VRIN) resources can acquire and apply additional resources towards competitive advantage for future performance. This theory supports the current study in articulating a systematic planning procedure for complete project cycle management including designing. This is in addition to the wider planning procedures of problem tree analysis, the development of objectives and indicators, and identification of risks and assumptions, which feed into the overall programme plan.

Performance of a project is considered as a source of concern to both public and private sector clients. Thomas (2010) defined performance measurement as monitoring and controlling of projects on a regular basis. He observed that project performance measurement includes time, budget, safety, quality and overall client satisfaction aided by project design tools. Bennett (2015) stated that a project performance measurement is related to many indicators such as time, budget, quality, specifications and stakeholders' satisfaction. They further stated that project performance measurement means an improvement of cost, schedule, and quality for design and construction stages.

Improving project performance in the community poses several challenges for stakeholders. Additionally, it is not an easy task to sustain radical improvement in a diverse environment. It requires the identification and implementation of suitable improvement programmes subjected to the community business cycle (Wellman, 2011). This is important since the integration of improvement programmes in a community may lead to high cost and yet the benefit can only be realized in the long term. However, there is a need for new improvement programmes and initiatives at various stages of a project life-cycle in order to enhance community project performance and target changing trends of private and public sector project organizations (Thake, 2012). Project performance can be affected by a range of things; one of these being the organizational structure of the business (Paul, 2010). As mentioned, it has been observed that the most successful way of exploiting a strategic opportunity or implementing a change in a company is through a temporary process or structure for example, a project team focused on the project task and objectives in order to solve a problem or implement a new strategy (Chizimba, 2013).

Performance of CBPs in Kenya remains wanting largely due to limitations such as finance, constraints of the environment and lack of management and technical expertise (Odindo, 2009). Moreover, constant pressures of fundraising, weak management skills and difficulties in scaling-up operations can limit CSPs' effectiveness and accountability. Silverman (2008) indicated that aspects such as local networks of CBPs, leadership, client characteristics, staff and strategy can have an influence on the success of their programmes. The development and exploitation of managers' social networking relationships with external entities affects performance of those organizations. Such social networks create social capital for organizations by establishing avenues for the exchange of valuable information, resources, and knowledge (Thake, 2012).

\section{RESEARCH METHODOLOGY}

The main philosophical underpinning of this study is the pragmatism derived from the work. This study used the descriptive survey research design. The target population for this study was 15 projects which met the study criteria from the total number of community based projects in Kenya which was 96. The study sought to sample 128 chosen randomly from the target population. The research instruments that were used for the survey was a structured questionnaire supplemented by an interview guide. The study generated both qualitative and quantitative data. Quantitative data was coded and entered Statistical Packages for Social Scientists (SPSS Version 21.0) and analyzed using descriptive statistics. Qualitative data was analyzed based on the content matter of the responses. Responses with common themes or patterns were grouped together into coherent categories. Descriptive statistics involved use of absolute and relative (percentage) frequencies, measures of central tendency and dispersion (mean and standard deviation respectively). Quantitative data was presented in tables and graphs and explanation was presented in prose. The study used Spearman correlation to establish the relationship between the independent variable and the dependent variable.

\section{RESEARCH RESULTS AND DISCUSSIONS}

The study was to examine how the application of problem tree analysis influences performance of community based projects. This section focused on project problems identified, project root causes and project effects. Project identified problems was measured by providing respondents with statements rated on a five-point Likert scale ranging from: Strongly Disagree (SD); Disagree (D); Neither Agree nor Disagree (NAD); Agree (A) and Strongly Agree (SA) from which to choose. The findings are presented in Table 1.

TABLE 1 PROJECT IDENTIFIED PROBLEMS AND PERFORMANCE OF COMMUNITY BASED PROJECTS

\begin{tabular}{lccc}
\hline Statements & Mean & SDV \\
\hline Constraints to the problems are identified & 4.6505 & 0.94670 \\
$\begin{array}{l}\text { The main problem is always selected } \\
\text { among other community problems }\end{array}$ & 4.7767 & 0.69919 \\
$\begin{array}{l}\text { Consensus building is done when } \\
\text { identifying the right problem }\end{array}$ & & \\
$\begin{array}{l}\text { Our organization identifies the right } \\
\text { schedules for problems identified }\end{array}$ & 4.7379 & 0.89649 \\
& & & \\
Identified problems are well defined & 4.5631 & 0.97689 \\
\hline $\begin{array}{l}\text { Composite for Project-identified } \\
\text { Problems }\end{array}$ & $\mathbf{4 . 7 0 2 9 2}$ & $\mathbf{0 . 8 4 2 8 4}$ \\
\hline
\end{tabular}

The study results show that majority of the respondents strongly agreed $(\mathrm{M}=4.65, \mathrm{SDV}=0.95)$ that constraints to the problems are identified. They also agreed $(\mathrm{M}=4.78$, 
$\mathrm{SD}=0.70$ ) that the main problem is always selected among other community problems. Respondents strongly agreed $(\mathrm{M}=4.79, \mathrm{SDV}=0.70)$ that consensus building is done when identifying the right problem. The participants strongly agreed $(\mathrm{M}=4.74, \mathrm{SDV}=0.90)$ that their organization identifies the right schedules for problems identified and they strongly agreed $(M=4.56, S D V=0.98$ that identified problems are well defined. Overall, the surveyed employees agreed $(\mathrm{M}=4.70$, $\mathrm{SDV}=0.84)$ that project-identified problems influence community based project performance. The results imply that identification of project problems is very important in the performance of community based projects since this enables the community to focus on projects where have problems identified.

Project root causes were measured by providing respondents with statements rated on a five-point Likert scale ranging from: Strongly Disagree (SD); Disagree (D); Neither Agree nor Disagree (NAD); Agree (A) and Strongly Agree (SA) from which to choose. The findings are presented in Table 2.

TABLE 2 PROJECT ROOT CAUSES AND PERFORMANCE OF COMMUNITY BASED PROJECTS

\begin{tabular}{|c|c|c|c|}
\hline Statements & Mean & SDV & $\begin{array}{l}\text { community based project performance. The results imply that } \\
\text { project effects are very important in the performance of }\end{array}$ \\
\hline $\begin{array}{l}\text { Factors contributing to the problem are always } \\
\text { analyzed }\end{array}$ & 4.5825 & 1.05277 & $\begin{array}{l}\text { community based projects since without them projects cannot } \\
\text { function properly. }\end{array}$ \\
\hline Culture misalignments are identified & 4.1650 & 1.34381 & \multirow{5}{*}{$\begin{array}{l}\text { Correlational analysis using Pearson's Product Moment } \\
\text { technique was done to determine the relationship between } \\
\text { problem tree analysis and performance of community based } \\
\text { projects. It was meant to identify the strength and direction of } \\
\text { the association between the indicators of problem tree } \\
\text { analysis and performance of community based projects. The } \\
\text { results are summarized in Table } 4 \text {. }\end{array}$} \\
\hline Causes of main problem are identified & 4.1068 & 1.39967 & \\
\hline Problem is always defined & 4.6311 & 0.88551 & \\
\hline Data collected is always analyzed & 4.7184 & 0.69193 & \\
\hline Composite for Project Root Causes & 4.44076 & 1.07473 & \\
\hline
\end{tabular}

The study results show that majority of the respondents strongly agreed $(\mathrm{M}=4.58, \quad \mathrm{SDV}=1.05)$ that factors contributing to the problem are always analyzed. They also agreed $(\mathrm{M}=4.17, \mathrm{SD}=1.34)$ that culture misalignments are identified. Respondents strongly agreed $(\mathrm{M}=4.11$, $\mathrm{SDV}=1.40$ ) that causes of main problem are identified. The participants strongly agreed $(\mathrm{M}=4.63, \mathrm{SDV}=1.89)$ that problem is always defined; and they strongly agreed $(\mathrm{M}=4.72, \mathrm{SDV}=0.69$ that data collected is always analyzed. Overall, the surveyed employees agreed $(\mathrm{M}=4.44$, $\mathrm{SDV}=1.07$ ) that project root causes influence community based project performance. The results imply that project root causes are very important in the performance of community based projects since without them it will not be easy to define projects and plan to undertake them.

Project effect was measured by providing respondents with statements rated on a five-point Likert scale ranging from Strongly Disagree (SD); Disagree (D); Neither Agree nor Disagree (NAD); Agree (A) and Strongly Agree (SA) from which to choose. The findings are presented in Table 3.
TABLE 3 PROJECT EFFECT AND PERFORMANCE OF COMMUNITY BASED PROJECTS

\begin{tabular}{lll}
\hline Statements & Mean & SDV \\
\hline Proactive plans are done to mitigate effects & 4.5825 & 1.05277 \\
Effects of the main problems are identified & 4.1650 & 1.34381 \\
Immediate effects are identified & 4.1068 & 1.39967 \\
Long-term effects are identified & 4.6311 & 0.88551 \\
Cause-effect analysis exists & 4.7184 & 0.69193 \\
\hline Composite for Project Effects & $\mathbf{4 . 4 4 0 7 6}$ & $\mathbf{1 . 0 7 4 7 3}$ \\
\hline
\end{tabular}

The study results show that majority of the respondents strongly agreed $(\mathrm{M}=4.58, \mathrm{SDV}=1.05)$ that proactive plans are done to mitigate effects. They also agreed $(M=4.17$, $\mathrm{SD}=1.34$ ) that effects of the main problems are identified. Respondents strongly agreed $(\mathrm{M}=4.11, \mathrm{SDV}=1.40)$ that immediate effects are identified. The participants strongly agreed $(\mathrm{M}=4.63, \mathrm{SDV}=0.89)$ that long-term effects are identified, and they strongly agreed $(\mathrm{M}=4.71, \mathrm{SDV}=0.69$ cause-effect analysis exists. Overall, the surveyed employees agreed $(\mathrm{M}=4.44, \mathrm{SDV}=1.07)$ project effect influences community based project performance. The results imply that project effects are very important in the performance of community based projects since without them projects cannot unction properly. technique was done to determine the relationship between problem tree analysis and performance of community based analysis and performance of community based projects. The

TABLE 4 CORRELATION MATRIX FOR PROBLEM TREE ANALYSIS AND PERFORMANCE OF COMMUNITY BASED PROJECTS

\begin{tabular}{lll}
\hline & $\begin{array}{l}\text { Performance of } \\
\text { community } \\
\text { based projects }\end{array}$ & $\begin{array}{l}\text { Application } \\
\text { of Problem } \\
\text { Tree } \\
\text { Analysis }\end{array}$ \\
\hline $\begin{array}{l}\text { Performance of community } \\
\text { based projects }\end{array}$ & 1 & $-0.50 *$ \\
\hline $\begin{array}{l}\text { Application of Problem Tree } \\
\text { Analysis }\end{array}$ & $-0.50 *$ & 1 \\
\hline *Correlation significant at 0.05 level (2 tailed) &
\end{tabular}

The correlation results in Table 4 depicts that the indicators, namely, project problems identified, project root causes and project effects all of which were transformed into the composite variable problem tree analysis had some level of inverse association with performance of community based projects. The Pearson moment of correlation coefficient of 0.50 meant that the problem tree analysis had a moderately high negative correlation with performance. This implied that the more the problem tree analysis is implored onto the project implementation the more the reduction in performance levels of the projects. 
TABLE 5: MODEL SUMMARY FOR APPLICATION OF PROBLEM TREE ANALYSIS

\begin{tabular}{lllll}
\hline Model & & $\mathrm{R}$ & R Square & $\begin{array}{l}\text { Adjusted } \\
\text { Square }\end{array}$ \\
dimension & 1 & 0.462 & 0.214 & 0.19 \\
\hline
\end{tabular}

a. Predictors: (Constant), Problem Analysis

Table 5 presents the regression model summary on application of problem tree analysis versus the performance of community based projects in Bungoma County. As presented in the table, the coefficient of determination $\mathrm{R}$ square is 0.462 and $\mathrm{R}$ is 0.214 which is taken at 0.05 - level of significance. The Coefficient of determination $\mathrm{R}$ indicates that $21.4 \%$ of the variations in performance of community based projects are explained by the application of problem tree analysis. This implies that there exists a significant relationship between application of problem tree analysis and performance of community based projects in Bungoma County.

TABLE 6: ANALYSIS OF VARIANCE (ANOVA) FOR PROBLEM TREE ANALYSIS

\begin{tabular}{lllllll}
\hline Model & & $\begin{array}{l}\text { Sum of } \\
\text { Squares }\end{array}$ & df & $\begin{array}{l}\text { Mean } \\
\text { Square }\end{array}$ & F & Sig. \\
\hline 1 & Regression & 16.930 & 3 & 5.643 & 8.971 & .000 \\
& & & & & & \\
& Residual & 79.749 & 99 & .806 & & \\
& Total & 96.680 & 102 & & & \\
\end{tabular}

a. Dependent Variable: Performance of community based projects

b. Predictors: (Constant), Application of Problem Tree Analysis

The analysis of variance (ANOVA) results as shown in Table 6 above confirms further that the model fit is appropriate for this data since the $\mathrm{p}$-value of 0.00 is much less than 0.05 . This implies therefore that the overall $F(8.971)$ with $p<0.05$ indicates that we rejected the Null hypothesis and showed that there exists a significant relationship between the application of stakeholder analysis and performance of community based projects in Bungoma county.

TABLE 7: REGRESSION COEFFICIENTS: PROBLEM TREE ANALYSIS

\begin{tabular}{|c|c|c|c|c|c|c|}
\hline \multirow{2}{*}{ Model } & & \multicolumn{2}{|c|}{$\begin{array}{l}\text { Unstandardized } \\
\text { Coefficients }\end{array}$} & $\begin{array}{l}\text { Standardized } \\
\text { Coefficients }\end{array}$ & \multirow{2}{*}{$\mathrm{t}$} & \multirow{2}{*}{ Sig. } \\
\hline & & B & $\begin{array}{l}\text { Std. } \\
\text { Error }\end{array}$ & Beta & & \\
\hline & (Constant) & 3.22 & 0.534 & & 6.033 & 0.000 \\
\hline 1 & $\begin{array}{l}\text { Problem } \\
\text { Tree } \\
\text { Analysis }\end{array}$ & $\begin{array}{l}- \\
0.452\end{array}$ & -0.111 & -0.439 & $\overline{4}-079$ & 0.00 \\
\hline
\end{tabular}

a. Dependent Variable: Performance of Community based projects

The results in Table 7 further indicated that the application of stakeholder analysis has a negative significant influence on performance of community based projects. The fitted regression model $\mathrm{Y}=3.22-0.452 \mathrm{X}$. This implies that for every unit increase in application of problem tree analysis the level of performance of community based projects decreases by 0.452 . Even when application of problem tree analysis is not $_{\mathrm{R}}$ applied, the performance of community based projects would Stdi Frior offitheifstimate at 3.22 units. This indicates that there were still other factors driving performance such as logical0.89737nework, application of Gantt charts, and stakeholder analysis and managers competencies among others.

\section{CONCLUSION AND RECOMMENDATIONS}

\section{A. Conclusion}

The indicators for the application of problem tree analysis were identified problems, root causes and effects. The most dominant indicator was project problem identified, followed by project root causes and project effects. The results indicate that problems identified had a statistically significant influence on the performance of community based projects. Testing for project root causes had no statistically significant influence on the performance of community based projects Project problem effects had no statistically significant influence on the performance of community based projects. Overall, the application of project tree analysis had a statistically significant influence on the performance of community based projects.

\section{B. Recommendations}

Given that the application of problem tree analysis had an influence on the performance of community based projects, it is the organization's quest to ensure that there is a proper definition of the project framework. Those in charge must involve the relevant stakeholders in developing the problem analysis tree. This is because participation ensures efficiency as people form a pool of resources to meet common goals. Problem tree analysis is not only a critical performance determinant, but effectiveness is also increased by giving stakeholders a right in planning for and designing the project.

\section{REFERENCES}

A.A. Abegunde, "Rethinking Polarization of Raw-Material Inputs to region Centers: A Panacea to Rural Economic Development". Environment and Behavior. Adekunle et al (eds) EBAN. 2003

K.G. Campbell, (August 2006). The Problem Tree. Analysis of the causes and effects of problems. Accessed: 10.08.2010.

A. Chimwazo, Analysis of factors influencing project cost overruns in Botswana. Construction Management and Economics, 18(1), 7789. 2005

J. Creswell, "Research design: Qualitative, quantitative and mixed method approaches" (2nd ed.). California: Sage. 2013

T. Hill, Operations management. New York, NY: Palgrave MacMillan. 2015

H. Kerzner, Project Management: A Systems Approach to Planning, Scheduling, and Controlling. John Wiley \& Sons, 2009

T. Kikwasi, T., and W. Chirunga, Causes and effects of delays and disruptions in Tanzanian construction industry. African Journal of Management, 213-225. 2012

G.D.Larson, Significance of project management structure on development success . IEEE Trans EngManage, 36. 2009

J.P. Lewis, Fundamentals of Project Management. 3rd ed, New York: AMACOM .2017

P. McCawley, "Problem Tree Analysis: a centenary appreciation by project managers. European Journal of Operational Research, 13(9), 231236. 2014

K.McKay, The human factor in planning and scheduling, in Handbook of Production Scheduling J.W. Herrmann,ed., Springer, New York. 2016

MDF. MDF Tool: Problem Tree Analysis. Ede: MDF Training and Consultancy.2005 [Accessed: 10.08.2010]. 
S. Nyandemo, Project management from design to implementation approach guide for successful project management Richard Designer and prints, Nairobi, Kenya. 2010

M. Odindo, Capacity Needs of Community Based orgaisatin in Kenya to apply for Global Fund Grants. Cologne. 2009

T. Ooko, The impact of teamwork on the achievement of targets in organizations in Kenya: a case of SOS children's villages, Eldoret. Unpublished Master's thesis Moi University Kenya. 2013

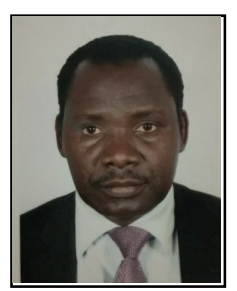

Wasike Wilberforce Walubengo is from Bungoma county in, Kenya $29^{\text {th }}$ May 1972. Kenyan based degrees :,PhD in Project planning and Management (planning, designing and implementations) from University of Nairobi 2019, Master's Degree in Business Administration (project management) from Kenyatta university 2015,Post Graduate Diploma in monitoring and evaluation ,Mount Kenya University 2016 .Ugandan based Degrees :.Master's degree in monitoring and evaluation from Utamu University 2018 ,Bachelor of procurement and supply chain management from Busoga University 2013 ,Graduate Diploma from CIPS UK 2003.

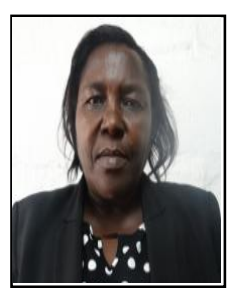

Dorothy Ndunge Kyalo is professor, Dean of School of Continuing and Distance Education, Senior lecturer in the department of Extra Mural Studies at the University of Nairobi, Kenya. Supervises research work at both master's and $\mathrm{PhD}$ levels. Coordinator $\mathrm{PhD}$ in Project Planning and Management (PPD\&I Option). A Handbook for Students and Practitioners. Nairobi, Kenya, Aura Books, 2012, Role of school leadership in promoting moral integrity among Secondary School students. VDM Verlag Dr. Müller Aktierge Sellschaft \& CO.KG, Germany,2011, Project Planning and Management: Notes for Beginners, DM Verlag Dr. Müller Aktierge Sellschaft \& CO.KG, Germany 2011. Previous research interest was in education administration and current research interest in project management

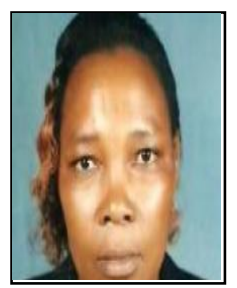

Dr Mulwa is a registered member of Kenya Association of Project Managers; Membership Number-048 and registered member of International Project Monitoring and Evaluation Society; Membership No. FY073117

Publications: Mburugu K. N; Mulwa, A. S. and Kyalo, D.K. (2015). Influence of Organizational Strategy on Implementation of Electronic Project Monitoring Information System in Public Tertiary Institutions in Kenya. International Journal of Research and Development Organization (IJRDO) Vol.2 ISSUE 9, Eliud, S. M.; Mulwa, A.S. and Kyalo, D. N (2014). Access to Improved Sanitation: Implication for Sustainable Implementation of Hygiene Practices Secondary Schools in Machakos County, Kenya. Published in the European Scientific Journal, Vol. 10, No. 1.

BOOKS: Matula P.D, Kyalo D. N and Mulwa A.S. (2019). Instructional Supervision: Bridging Theory and Practice. University of Nairobi Press, Nairobi. Matula P.D, Kyalo D. N, Mulwa A.S, and Gichui, R.W.(2019). Academic Research Proposal Writing: Principles, Concepts and Structure. ARTS Press; Nairobi. Kyalo D. Matula P.D. and Mulwa A.S., (2016). Sociology of Education: Issues, Theories, Application, Revision Questions and Answers. Downtown Publishers and printers, Nairobi. 